\title{
Perspectivas literarias en la cuentística para niños de Carballido, Hinojosa y Molina*
}

\author{
Literary Perspectives on Short Stories for Children in Carballido, Hinojosa and Molina \\ Daniela Casas Sosa ${ }^{1}$ Carolina Rayo Montealegre ${ }^{2}$
}

Para citar este artículo: Casas, D.; Rayo, C. (2017). Perspectivas literarias en la cuentística para niños de Carballido, Hinojosa y Molina. Infancias Imágenes, 16(1), 104-117.

\section{Resumen}

El presente artículo reflexivo se enfoca en las características de la literatura infantil mexicana y cómo a través de estas se puede desarrollar un lazo más significativo relacionado con las vivencias de los niños.
Recibido: 23-mayo-2016 / Aprobado: 13-julio-2016

\begin{abstract}
This reflective article focuses on the characteristics of Mexican children's literature and how through those, it is possible to develop a more meaningful bond related to a child's experience. For this, we took into account some theoretical references that allowed us to analyse the work (stories) of three Mexican writers, with the aim of demonstrating how from different literary perspectives, can give a wider view at what should be contemporary narratives for children. In turn, we propose to break with the imaginary of what has been the children's literature, framed largely in pre-established topics that have deepened little in the real and daily situations of the smallest.
\end{abstract}

Keywords: Latin American literature; short stories; literary analysis; censorship; cultural conditions.

Palabras clave: literatura latinoamericana; cuento; investigación literaria; censura; contexto cultural. [UNESCO Thesaurus http://vocabularies.unesco.org/browser/ thesaurus/es/]

\footnotetext{
* Artículo de reflexión. El siguiente trabajo presenta los resultados de una reflexión teórico-literaria: fue realizado en Ciudad de México en julio de 2015 y culminado en la Universidad Distrital Francisco José de Caldas en marzo de 2016.

1 Licenciada en Educación Básica con Énfasis en Humanidades y Lengua Castellana. Correo electrónico: danielala612@gmail.com

2 Licenciada en Educación Básica con Énfasis en Humanidades y Lengua Castellana. Correo electrónico: carolinamy95@gmail.com
} 


\section{Introducción}

La vida en la vida en nada se parece a la vida en los cuentos...

y es que la historia de la literatura abunda en finales felices.

(Francisco Hinojosa, 2005).

Este artículo reflexivo trata sobre las nuevas perspectivas que se dan en torno a las vivencias y contextos de los niños, presentes en las temáticas de los cuentos infantiles mexicanos de los autores elegidos. En ese sentido, se indagan los tópicos que tradicionalmente han definido la literatura para ellos y se contrastan con las características encontradas en los cuentos seleccionados. Con ello se busca dar a conocer un panorama diferente acerca de las narraciones literarias para los más pequeños y, así mismo, generar una nueva visión para futuros escritores y a su vez lectores de literatura infantil.

De esta forma, la estructura del presente texto aborda en primera instancia el tema de la censura y los paradigmas presentes en las historias tradicionales de los cuentos de hadas. Posteriormente, se esboza brevemente un perfil de los escritores seleccionados. Luego se tratarán los referentes teóricos desde los cuales se analizan las obras de los autores y se presentan las temáticas emergentes de su narrativa, configurando la misma con aspectos sociales, políticos y culturales. Por último, se expone la conclusión en la cual se evidenciará la importancia del tratamiento de temáticas censuradas en la literatura infantil al propiciar un vínculo entre la realidad y la ficción.

En este orden de ideas, la teoría de la recepción fue la perspectiva literaria usada para el análisis realizado a los cuentos infantiles seleccionados. Esta le asigna un rol más importante al lector, ya que en otras teorías no era tomado en cuenta. Hans Robert Jauss y Wolfang Iser toman parte del triángulo semiótico en el cual se reconoce el emisor, el medio de comunicación y el receptor. Los teóricos convirtieron a este último en el eje central de la teoría de la recepción y en el sujeto que percibe y transforma la obra en el momento en que la lee y la interpreta.

Por otra parte, Harald Weinrich relaciona el papel del lector directamente con el de la obra literaria ya que implica un proceso de producción por parte del autor, pero de recepción por parte del lector, construyendo una relación dicotómica en la que uno no existe sin el otro. De esta manera, se genera una interacción entre receptor y emisor que permite que la obra pueda ser influenciada por aspectos históricos, culturales y sociales. En otras palabras, "la obra vive mientras produce un efecto" (Jauss, 1986), de esta forma el lector puede dar diversas interpretaciones del texto de acuerdo a su percepción y apreciación demostrando que la obra puede tener varias lecturas que definen su polisemia.

Existen dos tipos de lectura: la interna, implicada por la obra y el entorno que aporta el receptor desde su contexto, y la reflexiva, en la que el lector experimenta un goce o disfrute estético al reconocer situaciones de la vida a lo largo del proceso lector, estas situaciones lo afectan directamente. Para Iser "La lectura se convierte sólo en placer allí donde nuestra productividad entra en juego" (citado en Gadamer, 1992), es decir, que solo se dan procesos interpretativos en el momento que se genera una lectura reflexiva de la obra.

En ese sentido, se busca que la interpretación recaiga sobre el lector al brindar libertad y autoridad sobre el texto al interpretarlo, desarrollando un acto de correlación entre la obra, el autor y el lector de modo que se logre una lectura completa. Cabe mencionar que al acercarse a la lectura de un texto se tienen ideas preconcebidas, experiencias y conocimientos anteriores que ejercen influencia al iniciar la lectura. Por ello, el significado que el lector le asigne a la obra esta mediado por una serie de referencias externas que contribuyen al proceso de formación de la experiencia humana.

\section{Metodología}

En ese orden de ideas, se realizó una lectura de algunas obras infantiles de escritores mexicanos, se seleccionaron los cuentos de acuerdo con las relaciones que se construían en las obras teniendo en cuenta aspectos contextuales y sociales de la infancia latinoamericana. Luego se indagó por el autor y el contexto en el que fue escrita la obra para iniciar con el análisis de los cuentos, llevando a cabo una interpretación según la teoría de la recepción. Durante este análisis se elaboró una 
hipótesis sobre el significado de los textos, sacando algunas inferencias y concepciones implícitas entre las historias de las obras y las vivencias de los niños. Posteriormente, se recurrió a conocimientos generales sobre los cuentos de hadas y los cuentos infantiles analizados, con el fin de establecer un paralelo que permitió desarrollar las interpretaciones y percepciones de los cuentos. Por último, se concretizaron las obras, es decir, se complementó el sentido de cada uno de los cuentos a partir de la lectura realizada.

\section{En un mundo muy muy feliz...}

En un mundo muy muy lejano, tan lejano como la vuelta de la esquina, se encuentra un camino con dimensiones mágicas y cotidianas. Muchos de los que pasan por allí se chocan con hadas, duendes, fantasmas, unicornios, mundos perfectos con gente perfecta y finales perfectos. Pero otros solo ven un camino al cual se puede llegar a casa, un camino común y corriente que tiene sus dificultades y aventuras a medida que se avanza. Ese camino es el reflejo de los rasgos que puede llegar a tener un cuento infantil, algunos de ellos son tratados de magia y otros encuentran en lo cotidiano formas que hacen sentir identificados a los niños dentro de sus historias. No por eso los cuentos que entre sus páginas presenten hadas, duendes y castillos pierden su validez, o su encanto, pero no pueden ser el estereotipo de todas las historias y es que al final de cuentas un final no feliz, y real, también es válido.

En la enredadera entre lo ilusorio y lo real se hallan obras que rescatan lo cotidiano de la vida y le añaden un poco de risa, juego y aventuras. En algunos casos, la línea de lo mágico se combina con diferentes aspectos comunes y corrientes que se pueden hallar en cualquier lugar. Más allá de mostrar una serie de eventos fantásticos en los que siempre la justicia, el amor y la amistad triunfan también es necesario enseñar que el engaño, la desilusión, la injusticia y el desamor son cosas que trae consigo el mundo y forma parte del proceso de crecer encontrar una forma de enfrentarlas.

Al respecto, Francisco Hinojosa decía que parece ser que un final que no sea feliz no es válido, o más bien, no se vale uno en el que durante toda la historia se apunte al triunfo de la justicia más elemental y al concluir se transforme sin ninguna excusa en cierta victoria de la injusticia y la arbitrariedad, dejando al lector aparentemente desilusionado por tan desdichado final, sin darse cuenta de que lo que curiosamente se busca es permitir que los futuros adultos conozcan sobre los triunfos del mal y su existencia en un entramado de palabras, ilustraciones y caratulas.

De esta forma, se ahondará en las siguientes páginas sobre algunos cuentos de hadas que permiten observar una serie de elementos que salvaguardan el mundo de los finales reales, excluyendo temáticas escatológicas y creando un imaginario ilusorio en los niños.

Para empezar, se debería decir que desde un inicio se ha engañado al lector presentándole cuentos que relatan la utópica historia de amor entre un príncipe y una princesa, en la que, por lo general, ella es una pobre plebeya, juntos superan los obstáculos y tienen un "vivieron felices por siempre" (idea recurrente, copiada y malgastada por la mayoría de cadenas televisivas). No obstante, estas historias no fueron incubadas entre líneas de placidez y magia, como se le obliga a creer al lector: en otras ediciones y en las adaptaciones cinematográficas, la mayoría de sus versiones originales terminan con un desenlace trágico, ¿o es qué acaso se mencionó en algún momento que Mowgly ${ }^{3}$, en el libro de la selva, logra encontrar un aldea en dónde vivir pero que, debido al rechazo de los aldeanos, se enfurece y destruye la misma?, ¿o cómo la Bella Durmiente 4 no despertó precisamente por el beso de un príncipe encantado sino por el nacimiento de sus dos hijos, producto de la violación del mismo? O como sucede; en el innombrable final de la Sirenita ${ }^{5}$ en el que no obtiene el amor del príncipe, por lo que intenta matarlo y termina convertida en espuma del mar. Sin embargo, incluso estos cuentos se asemejaron en algún momento a la cruda realidad que tanto trataba de ocultar el círculo de protección infantil, pues Tarzán siempre andaba desnudo, Cenicienta llegaba a media noche, Pinocho mentía, la Bella dormía todo el día, Caperucita no hacía caso

\footnotetext{
3 Versión original de Rudyard Kipling (1894).

4 Versión original de Giambattista Basiel en: "Talía, sol y luna" (1634).

5 Versión original de Hans Christian Andersen (1837).
} 
a su mamá y paseaba con el lobo, Candy tenía dos novios, Popeye se metía hierba, Blanca Nieves vivía con siete hombres, y aun así todos terminaban en el ideal disfrazado del "vivieron felices por siempre".

Todos aquellos finales infelices nos hacen recordar lo humanos que somos y los episodios reales a los que constantemente nos enfrentemos, pero que siguen siendo censurados por la misma sociedad y sus aparatos ideológicos como las editoriales, las escuelas y la familia, quienes tal vez piensan que estos sentimientos deben ser reservados para la adolescencia y no afrontados en la niñez, pues solo en esta etapa sí sabrá resolverlos. En otras palabras, se envía a un mundo real con los ojos semivendados, sin anestesia, creyendo aún en el ideal quimérico de felicidad asegurada, tal como vislumbraba el filósofo colombiano Estanislao Zuleta en uno de sus ensayos.

Entonces comenzamos a inventar paraísos, islas afortunadas, países de cucaña. Una vida sin riesgos, sin lucha, sin búsqueda de superación y sin muerte. Y por tanto también sin carencias y sin deseo: un océano de mermelada sagrada, una eternidad de aburrición [...]. (Zuleta, 2000).

Sin embargo, según Bettelheim (2010), mientras algunos cuentos de hadas pueden conducir al niño a un final feliz desde las características psicoanalíticas que se encuentran en su contenido, otros son simplemente cuentos moralistas que solo cumplen la función de ser una mera distracción para el niño. Un ejemplo de ello se puede encontrar en Ricitos de oro, historia que no sigue fielmente las características de los cuentos de hadas, pues no hay un final aparentemente feliz para su protagonista y que, sin embargo, refleja simbólicamente las etapas más problemáticas del desarrollo de los niños, "la lucha contra los conflictos edípicos, la búsqueda de la identidad y la rivalidad fraterna" (Bettelheim, 2010, p. 253). Esta es una de las historias en las cuales no "todos viven felices por siempre", ya que, si bien relata episodios fantásticos, estos son más cercanos a la realidad a la que se enfrentan los niños quienes se ven obligados a buscar refugio y alimentación en hogares ajenos a los suyos.
En el mundo de los cuentos de hadas abundan los finales felices, por lo que la extraña promesa de encontrar uno en todos los relatos se vuelve de vital importancia para el lector. No obstante, esos finales solo pueden ocurrir dentro de la naturaleza de la imaginación, pues "el cuento de hadas ofrece al niño la certidumbre de que algún día llegará a conquistar un reino. Aunque al niño le cueste imaginárselo y no pueda creerlo, el relato le asegura que fuerzas mágicas acudirán en su ayuda" (Bettelheim, 2010, p. 160). Es decir, solo a través de esa fantasía se puede soñar con dicho final, pues de lo contrario se caerá en el abismo de la realidad.

Aunque la literatura infantil anhela el disfrute de dicha ficción esta solo puede establecerse bajo sus parámetros: todo lo que se encuentre fuera del canon literario infantil no es válido. En cambio, cuando se cobija bajo un ideal educativo y moralista, la narración se convierte en manual de enseñanza, propaganda pedagógica y texto instructivo de buenas costumbres. El problema con la literatura infantil convencional es que sus relatos no trascienden en el nivel imaginativo que ya tienen los niños, es por ello que los mismos encuentran goce en estas historias, pero no obtienen de ellas más que un placer momentáneo. Es decir, no encuentran ningún alivio a sus problemas inminentes en este tipo de narraciones, sino que, por el contrario, solo escapan de ellos de forma efímera.

Lo cierto es que en algunas ocasiones esa censura se debe a las temáticas que se puedan Ilegar a trabajar dentro del relato, cuando ningún tema debería ser vetado para los niños, siempre que este tenga un tratamiento adecuado. Volviendo a los ejemplos de cuentos clásicos enunciados con anterioridad, se pueden evidenciar situaciones terriblemente violentas, pero no por esto, en tiempos antiguos cuando no había adaptaciones ni cambios en las historias, estas dejaban de contarse.

En esta época es cuando han surgido las dudas, con frecuencias mojigatas y desinformadas, sobre lo que los niños pueden o no pueden saber. Ellos lo saben todo: oyen noticias y conversaciones. Ellos se preguntan y nos preguntan. Los adultos no 
contestamos porque no sabemos cómo hacerlo. (Córdova, 2015) $)^{6}$.

Se debe considerar que el error se encuentra en creer que así se protege a los niños de los terribles males de la vida, a los que, no obstante, tarde o temprano se deberán enfrentar a ellos, por lo que es mejor que obtengan una conciencia reflexiva en concordancia con su inteligencia emocional, herramientas que los cuentos les pueden brindar. Dichas historias censuradas traen consigo un objetivo proselitista, educativo y moralizante.

En definitiva, cuando alguna literatura con su juego de palabras convierte y deforma esas escatológicas temáticas en situaciones armoniosas y divertidas establece vínculos con las vivencias de los niños y se convierte en su compañía en el camino literario hacia el descubrimiento de la naturaleza del ser humano, con todas sus alegrías, emociones, fantasías y esperanzas, pero también con todos sus dolores, angustias, desesperaciones y desencantos.

\section{De la ficción a la realidad...}

De acuerdo con lo anterior, se presenta el análisis de los tres autores mencionados. El primero de ellos es Emilio Carballido ${ }^{7}$ (1925-2008), considerado uno de los dramaturgos mexicanos más importantes del siglo XX, el cual participó en la colección A la orilla del viento del Fondo de Cultura Económica, en donde publicó relatos para los niños que empiezan a leer. En su narrativa se aprecian historias relacionadas con la pobreza y la marginación. Dichas temáticas no las describe con pesimismo, sino, por lo contrario, hace una invitación a la risa seguida de la reflexión.

Este autor acertó al hacer literatura para niños ya que no se restringió al tratar temas censurados, al contrario, narró con pasión las historias que leemos adultos y niños. "Lo 'infantil' de su libro no está pues en el lenguaje sino exclusivamente en la imaginación fantasiosa que despliega el autor, quien recoge una vieja tradición de su tierra (Veracruz)" (Reyes, 2011).
Uno de sus principales escritos es La historia de Sputnik y David (1991), cuento en el que Carballido describe una interesante relación en la que David cuida y educa a su amigo el cocodrilo, enseñándole a comportarse como todo un niño normal, pero como es natural ambos crecen conforme pasa el tiempo y las actitudes del animal salen a flote, modificando la pasiva relación existente entre David y su familia. Una cadena de eventos desafortunados Ileva a la familia a imaginar distintos objetos elaborados con la piel del cocodrilo. Sin embargo, David muestra su posición de descontento y halla una solución: aferrado a la espalda de Sputnik, juntos fueron hasta el pantano, hábitat natural del reptil. David lo visita cada año o cada seis meses para saber de la vida de su amigo, conocer a sus esposas y a sus incontables hijos.

Los elementos más relevantes en este cuento son presentados al final, pues a lo largo de la historia es difícil imaginar que David y su amigo, quien lo había acompañado desde pequeño podía separarse de él y conformar un nuevo hogar, como sucede al concluir el relato. Este inesperado desenlace abre las puertas a diversas interpretaciones y distintas lecturas, fomenta la creatividad, la imaginación y la capacidad crítica de los niños.

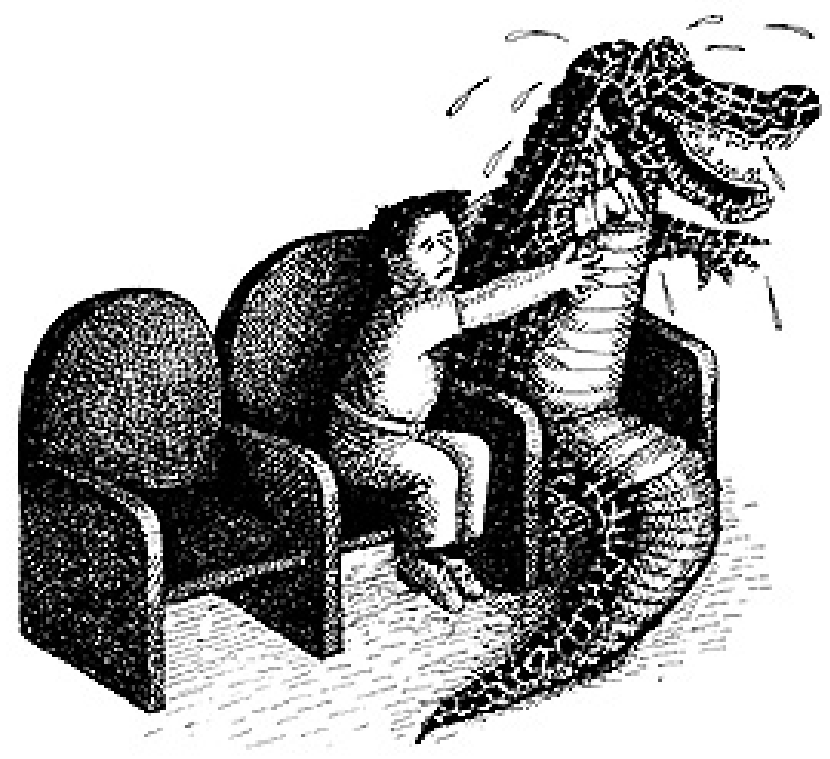

Figura 1. Carballido, E. (1991) La historia de Sputnik y David. Ilustración de María Figueroa.

Entrevista a Irene Vasco, escritora colombiana. 
Según Vásquez (2002), "El lenguaje que el niño encuentra en las obras literarias debe ser polivalente y sugerirle múltiples formas de aproximarse a la realidad que el autor ha creado". A lo largo del cuento se pueden analizar diversos temas, por ejemplo: en el apartado en que se separan David y Sputnik, el autor escribe: "A los que creen que las relaciones de dos especies tan distintas son imposibles y se acaban, voy a contar lo que siguió" (Carballido, 1991, p. 40), y siguió, que a pesar de las circunstancias estos dos personajes estuvieron en contacto manteniendo una relación de amistad infranqueable.

Esta pareja de amigos es un ejemplo de lo que significa asumir la diferencia, respetarla y entenderla para que de este modo todos construyamos una sociedad que se relacione en armonía, tolerando el entorno del otro y buscando encuentros que nos permitan escuchar y entender voces distintas a la nuestra. Por ello, la literatura infantil debe ser la mediadora en el encuentro entre el libro y el niño, permitiéndole que analice y viva las historias de acuerdo a como las siente, así se fortalecerá no solo su espíritu sino el círculo social que lo rodea.

Asimismo, en el final del cuento David, al ver las numerosas crías de su amigo Sputnik, expresa que aprendió la lección y solo tiene dos hijos. La decisión que tomó el personaje frente a la situación siembra en la conciencia de los niños la idea de la importancia de la paternidad y todo lo que ello implica. A su vez, se observa una postura social comprometida con lo que significa el crecimiento demográfico, teniendo en cuenta que México es una de las capitales del mundo con mayor número de habitantes. Por ello, es un avance bastante significativo que autores como Carballido traten este tipo de temáticas en la literatura, las cuales tienden un puente dialógico entre el relato y la realidad.

Igualmente, y en cuanto a la contribución de una narrativa que fortalezca los lazos literarios con las vivencias de los niños, este autor es fiel a la idea de Hinojosa relacionada con la necesidad de que no todos los cuentos culminen con un final feliz: "Esto es, no fueron felices para siempre, ni ellos ni los caimanes. Pero nadie lo es. Y en cambio, les daba alegría verse y estar juntos. Eso vale mucho"
(Carballido, 1991, p. 41). Si bien la literatura permite descubrir nuevas alternativas de ser y de ver el mundo, asimismo encontramos problemas reales que desde la niñez se deben encarar. Desde pequeños nos vemos permeados por factores históricos, políticos y sociales que determinan nuestro actuar y forjan nuestra identidad. Es por esa razón que el trabajo literario de este autor es relevante, pues reconoce la naturaleza humana de los niños y no oculta las situaciones que a diario deben sortear, ya que sería irrisorio pensar en la actualidad en un cuento de total felicidad, dirigido a un niño que tiene que trabajar todo el día en el transporte público, o un pequeño que tiene que presenciar cómo la violencia le arrebata sus tierras. Con ello, no se quiere decir que no deba existir la magia en la literatura infantil, de hecho, debe ser un elemento primordial, pero este componente mágico debe estar acompañado por un compromiso real: social y político.

En el cuento Los zapatos de fierro (Carballido, 1998), se narra la historia de María, una joven que mientras lava la ropa cerca del río ve una lechuguiIla que capta su atención. Decide tomarla y la bota al suelo y esta se convierte en príncipe, lo desencanta y como gesto de agradecimiento él decide proponerle matrimonio. Sin embargo, el esposo de María todavía no está exento de volver a ser hechizado, así, por las imprudencias de ella, su esposo sufre nuevos hechizos y emigra al país de "Irás y No Volverás". Debido a ello se calza un par de zapatos de fierro y emprende en su búsqueda. En el camino conoce a los Vientos del Norte y del Sur, a la Brisa, al Pajarero y a otros personajes que la ayudan a encontrar a su esposo.

[...] Sin moraleja, con sus retratos de la naturaleza humana en condiciones extremadas, una persistencia de cómo el amor es un esfuerzo de voluntad, capaz de borrar los años, y las distancias, y de gastar las suelas de los zapatos de fierro. (Carballido, 1998, p. 85).

La cita anterior da una idea del vuelco que Emilio le da a los temas convencionales en la literatura, sin intenciones de dejar una moraleja o enseñanza educativa con sus cuentos, nos permite 
leer un amor que resiste a condiciones extremas, que es paciente y persistente. Este cuento bien podría ser un ejemplo literario que refuta el postulado filosófico propuesto por Zygmunt Bauman (2005), quien crea una metáfora con las características de lo líquido y las relaciones actuales que corren y fluyen a una velocidad abismal. Bauman relaciona esa idea de lo líquido e inestable con la modernidad y el amor en la actualidad, porque en esta época de incertidumbre difícilmente se puede construir un amor sólido que continúe a pesar de las adversidades.

En estos tiempos de amores líquidos y de familias inestables, cuentos como estos rescatan la idea de las relaciones que superan los obstáculos que se presentan en el camino y los afrontan. No se encuentra un mejor aporte para los niños que este y es que continúen amando y queriendo, siendo conscientes de las relaciones que a diario construyen en su entorno. Si bien no todas les proporcionan felicidad es importante que dimensionen las com110 plejidades de las relaciones humanas $y$, asimismo, se ilusionen, creen, sueñen y iqué mejor motor que el amor para hacerlo posible!

Cabe mencionar que la representación femenina en los cuentos para niños tradicionalmente se ha enmarcado en unos estereotipos preestablecidos que impiden a la mujer desarrollar otras actividades diferentes a las que se han ordenado por tradición literaria infantil. La generación de nuevos lectores demanda replantear la figura femenina presente en dicha literatura: no se puede seguir alimentando la idea desdibujada en trazos previsibles o sin mayor complejidad y profundidad para los personajes femeninos y es debido a que las dinámicas sociales y de construcción a nivel familiar, económico y cultural se han modificado y la presencia femenina ha cobrado un impacto distinto, que merece la atención de los escritores para niños. Es en cuentos como Los zapatos de fierro que se presentan nuevas estrategias cuyo objetivo es intentar redefinir el imaginario infantil, proponiendo personajes femeninos independientes, aventureros y exitosos como el personaje de María.

Para concluir con este autor, abordaremos el cuento El pizarrón encantado (Carballido, 2007). Debido a que el padre de Adrián ya no vive con él, a causa de una enfermedad, su madre decide ir a visitarlo y él se queda como huésped en la casa de su tío. En uno de los juegos que hacen los niños, el personaje principal descubre en un sótano un pizarón y con él también la posibilidad de jugar con las palabras y crear cosas inimaginables. Poco después toma conciencia del poder que tiene el pizarrón y lo usa para curar a su padre y darle un mejor empleo. En el momento en el que todos descubren la magia contenida en aquel elemento, Adrián lo hace invisible y lo lleva consigo.

En este cuento en particular están presentes temáticas que en los anteriores no se habían tratado. Llama la atención el hecho de que se hiciera una crítica social en la que se referencia la problemática de los trabajadores ferrocarrileros, está explícito el tema de la huelga y la organización obrera por la lucha de los derechos de los trabajadores. El papá del protagonista y sus compañeros hacen

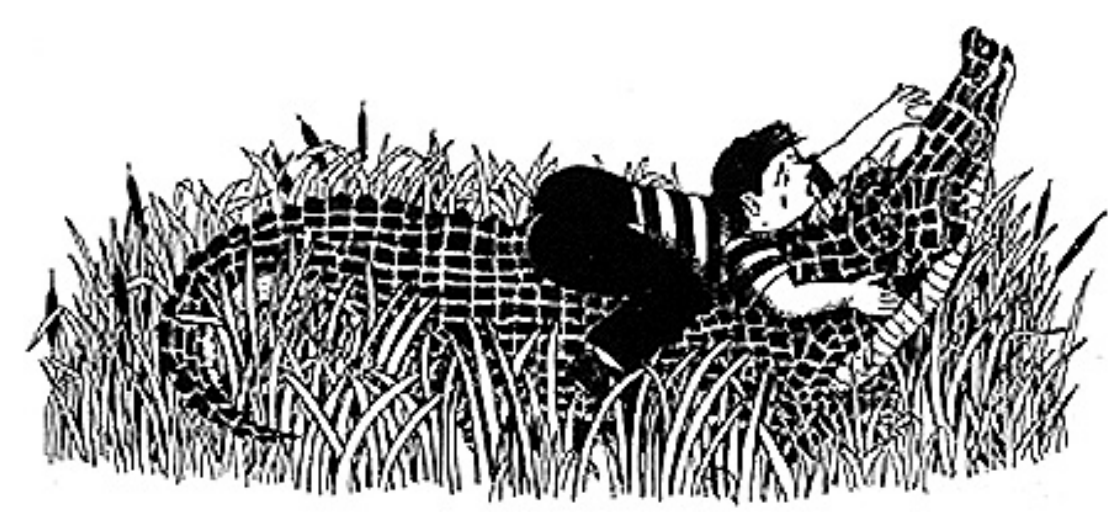

Figura 2. Carballido, E. (1991) La historia de Sputnik y David. Ilustración de María Figueroa. 
una huelga, esto es, dejaron de trabajar para pedir cosas justas y necesarias: más sueldo y beneficios para sus hijos y sus mujeres. Nada les conceden y mandan policías y soldados a pegarles (Carballido, 2007 , p. 3). A raíz de esto, el papá de Adrián se quedó sin trabajo y tiene que buscar empleo como bracero en otro país, desde entonces su mamá vela por él.

Es importante recalcar que los temas de los cuales escribe el autor, aterrizan a los niños en la cotidianidad del mundo real. Con seguridad no es solo Adrián el único niño que ha tenido que lidiar con no tener a sus padres por razones ajenas al núcleo familiar, sino más bien por problemas de tipo económico y laboral. Por ello, en países como los latinoamericanos es necesario que los niños se familiaricen con este tipo de problemáticas, ya que los va a convertir en sujetos más críticos y conscientes que actúen con relación a su entorno.

Él imaginaba lo mucho que aún podría jugar con su pizarrón. Y se decía algo más: cuando creciera, escogiendo bien las palabras, ¡cuántos cambios le podría hacer a la vida en torno, para volverla mejor. (Carballido, 2007, p. 40)

En definitiva, Emilio Carballido realizó un trabajo estupendo como escritor para niños, pues transgredió las normas y los temas comúnmente tratados y los relacionó con los contextos del público infantil, a su vez porque el lenguaje que usa es coloquial pero no deja de ser estructurado. La tarea de la escritura artística del autor no ha de copiar ni reflejar banalmente la realidad sino inventar una nueva en la que son los niños los personajes principales de la mágica cotidianidad. Es, por tanto, tarea para futuros escritores retomar el mundo de la vida cotidiana para recrear historias capaces de cuestionar y transformar su entorno.

Otras de estas narraciones infantiles son las elaboradas por el escritor mexicano Francisco Hinojosa $^{8}$. Nacido en la ciudad de México, en 1954, y con una carrera en lengua y literatura hispánica de la Universidad Nacional Autónoma de México

\footnotetext{
8 Escritor, profesor y poeta mexicano más destacado en el ámbito de la literatura infantil latinoamericana.
}

(UNAM). Se ha convertido en uno de los pioneros de la literatura infantil latinoamericana, su forma de transformar escenarios totalmente cotidianos en historias fantásticas Ilenas de diversión y risa lo han Ilevado a convertirse en becario del Fondo de Cultura Económica sin antes contar con una carrera exitosa como escritor de cuentos infantiles. Asimismo, criticó fuertemente las narraciones para niños que circulaban hacia los años 80 en México, pues según él mismo giraban en torno a princesas, animales, castillos y estaban escritas con diminutivos.

Una de sus obras más famosas, y primeras, es $A$ golpe de calcetín (2000), la historia de un pequeño que debe vender periódicos para solventar las necesidades de su familia y cómo el destino y un juego de circunstancias lo llevan a convertirse en una persona exitosa.

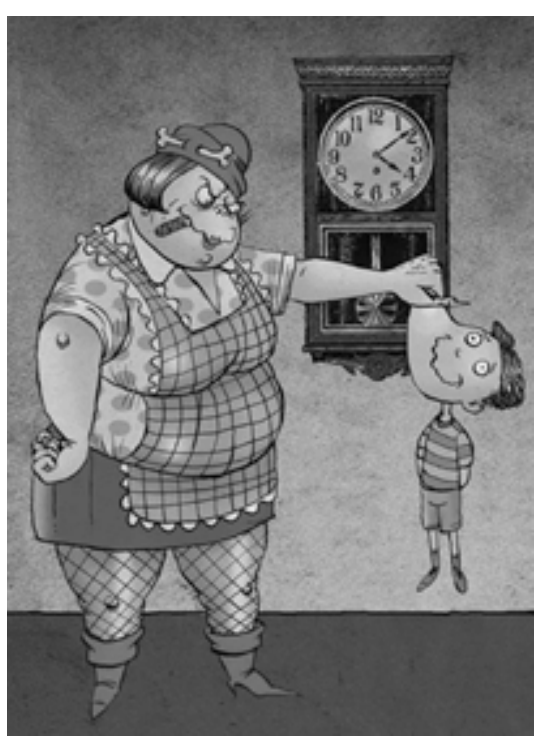

Figura 3. Hinojosa, F. (1992). La peor señora del mundo. Ilustración de Rafael Barajas.

Por esa misma linealidad, se encuentran la mayoría de sus obras, donde los niños son eso, niños con diferentes vivencias y situaciones, que pueden encontrar en ciertos detalles mundos divertidos, y un poco crueles, según la crítica "a fin de cuentas, para Hinojosa, los niños son, como dijo Freud 'perversos poliformos'" (Garralón, 2011). Este autor no se cohíbe al momento de escribir para los más pequeños y encuentra en los temas escatológicos su mayor inspiración, sin dejar de lado la vivacidad y el candor de los pequeños. Sus creaciones Ilenas 
de sátira demuestran la capacidad que tienen este tipo de relatos para despertar el interés literario en los mismos.

Las orejas de Urbano (Hinojosa, 2001) es otro de sus principales cuentos, en el que se narra la historia de Urbano un niño como todos los demás que solo se diferencia un poco por tener una de sus orejas más grandes que la otra, pero esto no lo hace ni menos ni más. Sin embargo, un día cuando se encuentra celebrando su décimo cumpleaños se da cuenta de que su oreja más grande escucha todo lo que hablan los demás, funcionando exactamente igual que las demás orejas, mientras que la más pequeña percibe lo que otros no oyen: los pensamientos de las personas. Eso lo lleva no solo a hablar sobre las situaciones penosas de sus conocidos, tildándolo en algunos casos como un niño mentiroso por poner en boca de él palabras que ni ellos mismos se atreverían a decir en voz alta, causándole gran incomodidad a ellos y divertidas situaciones a él.

112 En esta historia se puede reflejar la situación de un niño que tiene diferencias físicas y que, por ende, no deja de ser como cualquiera otro pues al tener una oreja más pequeña logra diferenciarse de los demás y, así mismo, lo convierte en alguien especial al poder escuchar el pensamiento de las personas, al confrontarlos con situaciones que quieren ocultar. Cosa que resulta demasiado incómoda para todos los adultos. Y es que en la vida real la mayoría de niños no tienen escrúpulos en decir lo que piensan y sienten de una forma directa.

Aspectos cotidianos son los que sobresalen en este relato, los cuales permiten que los niños se sientan identificados. El lenguaje sencillo y divertido de Hinojosa les hace creer que pueden leer o escuchar la historia de ellos mismos, con las cosas inoportunas que en algunos momentos puedan Ilegar a decir, sin importar las consecuencias que esas palabras traigan, para ellos no hay límites en cuanto a diversión se trata.

"Para él mismo, los extraordinarios poderes que tenía eran del todo inexplicables. De cualquier manera, la vida seguía su curso y nadie se tomaba en serio las locuras de un niño que aseguraba oír lo que pensaban los demás" (Hinojosa, 2001, p. 19).
El humor, la exageración y el absurdo de las cosas que desarrolla Hinojosa en sus narraciones crean algo tan fino e irónico que los temas prohibidos toman el papel principal. Por ejemplo: la represión y violencia por parte de una madre es un tabú que este autor destruye con humor negro en La peor señora del mundo (1992), el gusto por los bichos y los experimentos en La fórmula del Dr. Funes (1994) y el desencantamiento al amor y la muerte de Cupido en Poesía eras tú (2009).

En este sentido, demuestra que no existen manuales para hacer o escribir literatura infantil, que simplemente la necesidad de comunicar algo basta y que los nuevos contextos donde los niños nacen y crecen son muy diferentes a los que se relatan en las historias de hadas. Su labor como escritor no es la de develar todo a los niños, sino que ellos aprendan por sí mismos el placer que se encuentra en el acto de leer y con ello realicen diversas lecturas de su realidad en historias que tocan estos aspectos.

Por otro parte, la historia de $A$ los pinches chamacos (2005) expone un panorama de violencia que viven muchos niños a diario. Mariana, Ricardo y nuestro protagonista, que no tiene nombre predeterminado, son unos "pinches chamacos" a los que les gusta hacer travesuras. Un día excavan un pozo en busca de un tesoro, pero en su lugar encuentran huesos humanos y una pistola, elementos que desembocan en una serie de acontecimientos que lo llevan a conocer la calle, el hambre, el robo y la muerte como algo naturalizado de la vida misma.

Y ahora qué. ¿Lo matamos? Mariana se había abrazado de las piernas del señor Miranda para que no se moviera tanto. Ve si tiene balas. Sí, sí tiene balas. ¿Le damos un plomazo? ¿Qué es plomazo? Que, si lo matamos, buey. Sí, mátalo.

Pinches chamacos [...]. (Hinojosa, 2001, pp. 65-79).

El final feliz, la moraleja, el salvador y los duendes mágicos están obsoletos dentro de este crudo relato. El escritor comenta al respecto que los niños de hoy en día quieren leer sobre temáticas reales como la muerte, el divorcio y la diversidad sexual. Sin la imposición que puedan ejercer los mayores sobre algunos temas pues pareciese que el temor 
de los adultos a esas historias los asusta tanto que se termina censurando muchos libros sin saber de fondo que los niños y jóvenes sí saben diferenciar muy bien la realidad de la ficción.

Algunas de las ediciones para niños obedecen a las leyes que excluyen por completo la autenticidad de la obra literaria. Las editoriales terminan clausurando narraciones que probablemente ellos encontrarán fascinantes, que los incitaran a crear y a desarrollar un proceso inventivo en su lectura pues se apropiaran de nuevos lenguajes e ideas. Los pequeños no discriminan, pueden leer literatura desde cualquier perspectiva sin importar la etiqueta que les ponga el mundo adulto.

De acuerdo con lo anterior, el autor afirma, en una entrevista para el periódico Excelsior, que los lectores más pequeños ya no se chupan el dedo,

[...] Las historias para niños, en primer lugar, deben respetarlos; cuando un autor trata a un niño y le habla con diminutivos, quiere explicar demasiado las cosas o quiere venderle una idea que no es la que está tratando el cuento, los niños lo detectan; algo que a mí me funciona es ir muy directamente al grano, al clavo, lo que quiera decir lo digo y ya, sin rodeos, no me gusta usar palabras de más. (Sánchez, 2015).

Asimismo, destaca el papel de los escritores de literatura infantil haciendo énfasis en que deben omitir los aspectos pedagógicos que pretenden incluir en sus historias, deben tener cierto tipo de intuición, pero esta no debe ser en el reino de las enseñanzas. Entre más apartada esté la literatura de las moralejas clichés, los niños se interesarán más en acercarse a las narraciones, pues ellos detectan cuando se les quiere enseñar algo, y es que ese interés por moralizar todo no corresponde a los intereses literarios del pequeño sino a las peticiones y exigencias del gobierno, colegios y padres de familia.

Hinojosa expone un panorama diferente que transgrede con la idea que se tenía con relación a los temas tratados en la literatura infantil, pues los mismos siempre estaban íntimamente relacionados con seres mágicos, princesas y escenas que corresponden netamente a la ficción. Este autor apuesta por vivencias reales, crudas, descarnadas que están escritos para niños, lo cual demuestra su talento para transformar dichas temáticas en obras que abren el mundo literario para ellos y los encamina en un viaje de perspectivas tan diversas como la realidad misma. Con respecto a tocar temas actuales como la guerra y la violencia, Hinojosa pone como ejemplo a la escritora colombiana Irene Vasco, quien escribió un libro, para niños, sobre el secuestro, y tuvo una muy buena acogida por parte de ellos.

"Los niños de hoy toman en cuenta el que se les trate con respeto, antes pensábamos que los pequeños eran capaces solo de leer cuentos de hadas, princesas, castillos, duendes y hoy, pueden leer cualquier tema" (Hinojosa, 2005b).

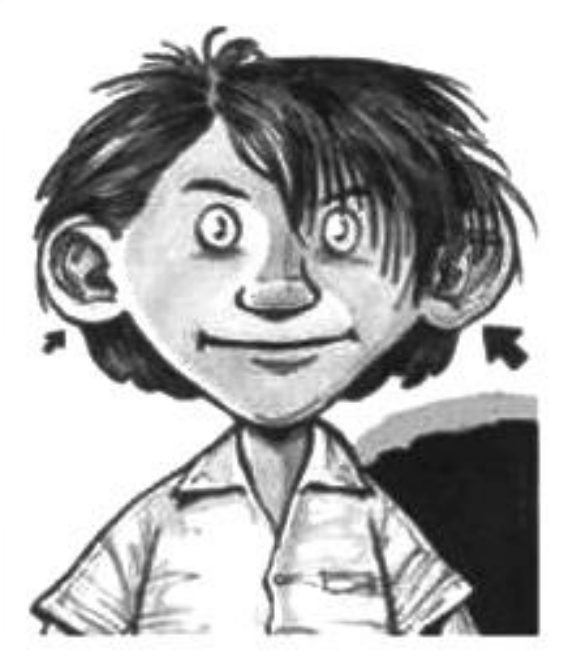

Figura 4. Hinojosa, F. (2001). Las orejas de Urbano. México: Alfaguara. Ilustración de Rafael Barajas.

En el mismo orden de ideas, se encuentra la escritora Alicia Molina9 ${ }^{9}$ oriunda de la Ciudad de México (1945). Realizó estudios en comunicación en la Universidad Iberoamericana, es escritora para el Fondo de Cultura Económica. Obtuvo el premio $A$ la orilla del viento en 1992 y actualmente dirige la Asociación Alternativas de Comunicaciones para Necesidades Especiales. Aunque no se encuentra mucha información acerca de esta escritora, se ha convertido en uno de los pioneros en combinar

\footnotetext{
9 Escritora y comunicadora social mexicana.
} 
temas reales, principalmente emocionales, con aspectos mágicos en sus historias infantiles.

Su cuento El agujero negro (2000) presenta la historia de Camila, una niña que debe pasar por una serie de episodios para encontrar el regalo perfecto para su madre, quien ha hecho rabietas y perdido mucho tiempo buscando las cosas que siempre pierde, entre ellas todos los regalos que le ha hecho su hija, por lo que hallar el regalo ideal se convertirá en todo un reto para Camila, y más cuando conoce al tramposo duende verde.

Al final de su historia no se plasma un final feliz en el que logra encontrar el regalo ideal, sino que demuestra que no siempre las cosas materiales son las que importan, que el hecho de devolver el tiempo a su madre, y los recuerdos de estos objetos de forma simbólica en un agujero negro, es mucho más valioso.

En esta historia queda demostrado que cualquier evento que se desarrolle durante el transcurso del día puede convertirse en una gran aventura,

114 al transformar cierto objeto en algo fantástico que permite superar los obstáculos que se presenten en la cotidianidad. Es decir, se lograr aprender a resolver los conflictos con las herramientas que se tienen al alcance, como el diálogo.

Siguiendo con esta trama, la autora crea dos cuentos más que tienen como principal protagonista a Camila y a su amigo el duende verde. La segunda historia se Ilama El zurcidor del tiempo (1996), la cual se da en el momento en que la protagonista debe enfrentar un nuevo problema: arreglar un cuaderno que le prestó la niña más juiciosa de la clase de matemáticas, pues está arruinado y ahora necesita la ayuda de los duendes para arreglarlo. El problema radica en que el duende desaparece y ella debe ir a buscarlo a través del tiempo por tres diferentes reinos: el Reino del Ayer, donde se encuentra con su mamá cuando era más pequeña; el Reino del Mañana, donde conoce a los hijos que tendrá; y el Reino de un Día, en el que conoce a los hermanos que hubiera tenido. Lo que permite que se cree una aproximada del niño y sus recuerdos por medio de las diferentes etapas por las que se pasa al crecer. La mayoría de pequeños piensa en cómo será su futuro cuando grandes, algunos ni se preocupan por ello, pero aun así esta escritora juega con los mundos del tiempo y por las etapas que deben pasar. Dentro de las cuales podrán encontrarse con grandes retos que deberán superar; un mal día puede lograr convertirse en uno aún peor, pero al final siempre será por el devenir de algo.

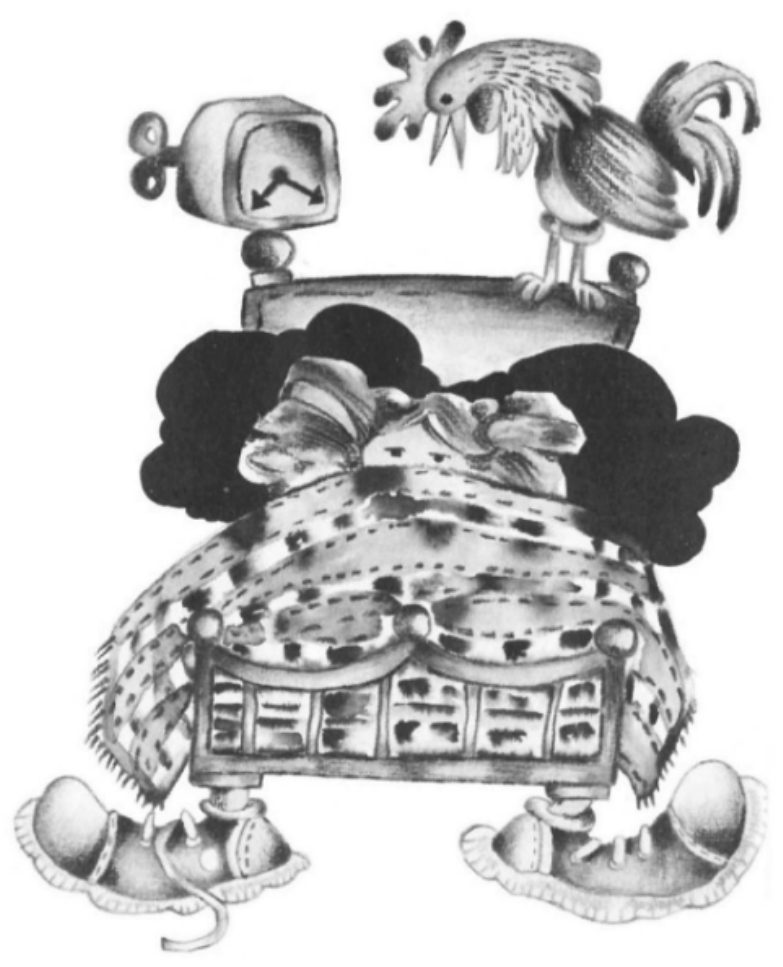

Figura 5. Molina. A. (1996). El zurcidor del tiempo. Ilustración de Enrique Martínez.

Alicia Molina pone como principal referente la forma en que se acercó al mundo de la escritura para a partir de ello crear historias. Narra que de pequeña era muy traviesa y sus padres no dejaban de regañarla por lo que le encantaba mentir y representar historias. Debido a esa inquietud y gran imaginación se convirtió en una pequeña muy mentirosa, sentía placer cuando las personas le creían los cuentos que inventaba y terminaba metiéndose en líos siempre. Su hermana un día la regañó bastante fuerte y le compró un cuaderno aconsejándola que en vez de decir mentiras las escribiera, encontrando así su vocación. Por lo que a la hora de desarrollar historias no teme en presentar a un pequeño malo y travieso que se sale con la suya ni en ver las diferencias infantiles como algo incorrecto. 
"Como que pasé de ser una niña mentirosa, a ser una niña imaginativa y eso fue muy padre" (Textos de Colores, 2013).

La literatura que representa no pretende realizar un encuentro didáctico donde los niños aprendan demasiadas cosas. Simplemente busca que se den cuenta de que temas como la discapacidad, las mentiras, la decepción y el fracaso son parte de su realidad, parte del mundo en el que viven y que, si quieren cambiarlo, tienen que dar un espacio y lugar a todo y a todos.

El libro El cristal con que se mira (2011) es protagonizado por tres niños con historias diferentes que se entrecruzan. Por un lado, está Emilia, un personaje que sufre una discapacidad auditiva por la cual debe utilizar aparatos para escuchar a sus amigos y seres queridos, pero que le ha permitido leer los labios. Por otra parte, se encuentra Diego, quien busca al padre que nunca conoció. Por último, Andrea, quien tiene muchos conflictos con su madre. Los tres se verán involucrados en una serie de episodios que los llevarán a ponerse en los zapatos del otro. Una especie de silencio social sobre la discapacidad y estas vivencias que tienen muchos niños a diario fueron la inspiración para que esta historia cobrara vida, convirtiéndose en la mejor forma de esta escritora para poner a los niños en el papel de otros pequeños.

La literatura que describe en sus historias permite que los niños se pongan en contacto consigo mismos y conozcan otras realidades diferentes, pero al mismo tiempo similares a las suyas, otras historias que logran enriquecer la propia. Tal como dice la autora:

Yo no veo éste como un proyecto pedagógico específicamente sobre la discapacidad, sino como un proyecto incluyente, que incluye a los niños con discapacidad. No se trata de darles una orden y lees, se trata de descubrirles un mundo. El camino es compartir lo que disfrutamos. (Macías, 2011).

Además del reto que enfrenta al escribir una narración realista que sea de interés para los pequeños, busca, como ella misma lo ha dicho, contribuir a una cultura de aceptación de la diferencia en la que ellos se den cuenta que hay semejanzas y diferencias en las personas que componen la sociedad y que actúan en la vida real, independientemente de las características, contextos, situaciones o discapacidad que muchas veces sean factor de segregación.

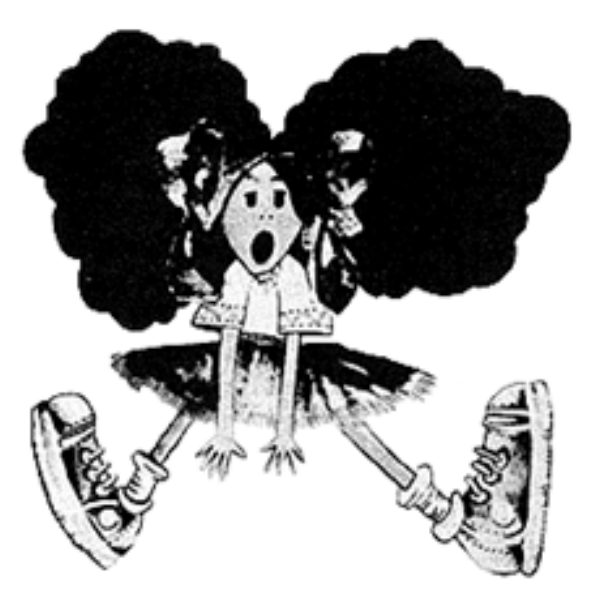

Figura 6. Molina. A. (1996). El zurcidor del tiempo. Ilustración de Enrique Martínez.

\section{No fueron felices para siempre (conclu-} siones)

El libro se convierte en una pequeña extensión de nosotros mismos, los pigmentos en él aparecen en nuestra piel y terminamos por fundirnos en ese olor a madera, en la suave textura de sus hojas, en el mar de palabras que lo componen. El alma se viste de múltiples colores y pronuncia un sinfín de sentimientos al compás y al ritmo de la música que leemos. Inevitablemente la lectura crea un puente con la realidad más inmediata, pero a su vez ilumina la mirada con cosas que jamás antes se habían imaginado. Algo extraño comienza a rondar alrededor del pensamiento, cuando tu mejor amigo es un cocodrilo cuyo nombre es Sputnik o podemos hacer magia con un pizarrón o debemos usar unos zapatos de fierro para recuperar el amor o convertirnos en héroes al leer los pensamientos de las personas con una pequeña oreja.

Entonces, la mente se abre a nuevas ideas y se concibe un mundo con variados elementos que confluyen entre sí: se reconoce al otro, se disfruta o se odia su compañía, se aprende a querer o aborrecer, a sentir miedo o deseo. Más que intentar compararse o asemejarse con los personajes de los cuentos estos enseñan cómo se puede superar 
cualquier dificultad, que, así como todos tienen diferentes particularidades, se enfrentan a problemáticas similares, aun así, se puede encontrar una salida entre risa y diversión. Los cuentos deben cumplir con presentar elementos a los niños que les permitan soñar, pero esos deben ir de la mano con sus vivencias, con la realidad próxima en la que se encuentran. Solo así se generará una cercanía que les permitirá adentrarse en el mundo de las narraciones infantiles. No hay que olvidar que el acto de leer es una aventura, en la cual, quien naufraga estará a la expectativa de lo que pueda pasar en el viaje, con incertidumbre de quedar a la deriva y emprender la tarea del lector.

A los niños se les debe hacer la invitación a que lean otro tipo de textos literarios, que rompan con los tradicionales. Pues son los típicos cuentos que empiezan con el: "Había una vez [...]" y terminan en el: "[...] y fueron felices para siempre" los que la escuela y los mismos padres han dejado a su alcance. Cuentos con temáticas y finales como los analizados retratan la intención lúdica propia del cuento y de la infancia, fomentan la creatividad y generan nuevas emociones en los niños que los ayudarán a descubrirse a sí mismos y a entender al otro. "La literatura es capaz de producir en el lector, también, emociones y sentimientos diversos y no solo la sonrisa alegre y el sueño tranquilo" (Hinojosa, 2005a, p. 103).

Es importante destacar el carácter polivalente de las obras que se seleccionaron, ya que lograron transgredir lo que leían los niños y por consiguiente desarrollar nuevas perspectivas en las que se involucran aspectos de su cotidianidad. Arriesgándose a realizar finales totalmente inesperados o narrando fina y armoniosamente realidades cotidianas cargadas de elementos fantásticos. Para retratar el mundo se debe luchar en contra de la inercia de la costumbre. No se trata de plasmar la realidad como tal o de adecuar un final feliz en cada historia, sino de redescubrir las riquezas del lenguaje en el día a día.

Se debe retomar la realidad con ironía y convertirla en un juego de goce y placer para los niños, sin dejar de lado lo que puedan aprender de algunas páginas en las que llegarán a descubrir historias tan normales como sus vidas mismas. Los cuentos mexicanos analizados que atañen este artículo permiten ver cómo el trato que se da a las historias modifican de manera radical los significados para los niños.

“En el fondo, el deber de educar consiste, al enseñar a los niños a leer, al iniciarlos en la lectura, en darle los medios de juzgar libremente si sienten o no la necesidad de los libros" (Hinojosa, 2005a, p. 112).

Finalmente, se anunciará una lista sobre las características que no se valen en la literatura infantil, siguiendo el ejemplo de Hinojosa (2005) y Pennac (2006).

- No se vale la censura porque un tema se crea inapropiado o poco entendible para el niño.

- No se vale siempre un final feliz para toda la vida.

- No se vale no hablar de lo grotesco de forma divertida.

- No se vale reprochar o tachar algún cuento solo porque sí.

- No se vale no leer todas las adaptaciones, por más distorsionadas de la historia real que estas estén.

- No se vale no transformar el callejón de la esquina en un lugar de aventuras.

- No se vale dejar de tener espíritu de niño.

- No se vale que algún niño en el mundo desconozca el poder de la literatura.

- No se vale no escribir.

- No se vale no fomentar el hábito de la lectura.

- No se vale leer sin cuestionarse por todo lo que se encuentra alrededor.

- No se vale no creer que la vida en sí misma con sus goces y sus angustias puede llegar a tener un final feliz real.

- No se vale creer que los cuentos para niños son solo para niños.

- Por último, pero no menos importante: no se vale dejar de soñar, ya sea con los ojos abiertos o cerrados.

\section{Referencias}

Bauman, Z. (2005). Amor líquido. Acerca de la fragilidad de los vínculos humanos. Buenos Aires: Fondo de Cultura Económica.

Bettelheim, B. (2010). Psicoanálisis de los cuentos de hadas. Barcelona: Crítica. 
Carballido, E. (1991). La historia de Sputnik y David. México: Fondo de Cultura Económica.

Carballido, E. (1998). Los zapatos de fierro. México: Fondo de Cultura Económica.

Carballido, E. (2007). El pizarrón encantado. México: Santillana.

Córdova, A. (2015). Terrorismo de Estado y libros para niños II. Linternas y bosques. Literatura infantil y juvenil. Recuperado de: https://linternasybosques.wordpress.com/2015/10/06/ terrorismo-de-estado-y-libros-para-ninos-ii/

Gadamer, H. G. (1992). Verdad y método I. $5^{\mathrm{a}}$ ed. Salamanca: Sígueme.

Garralón, A. (2011). Francisco Hinojosa, ese señor. Anataramba. Literatura Infantil. Recuperado de: http://anatarambana.blogspot.com.co/2011/07/ francisco-hinojosa-ese-senor.html

Hinojosa, F. (1992). La peor señora del mundo. México: Fondo de Cultura Económica.

Hinojosa, F. (2001). Las orejas de Urbano. México: Alfaguara.

Hinojosa, F. (2005a). Las estrategias de subversión en la narrativa infantil contemporánea. Altertexto. Revista del Departamento de Letras, 3(5): 97-116.

Hinojosa, F. (2005b). Los mejores lectores son menores de 12 años: Francisco Hinojosa. Fondo de Cultura Económica. Recuperado de: http:// www.fce.com.co/Prensa/Noticias/ArtMID/463/ ArticlelD/8066/Los-mejores-lectores-son-menores-de-12-a241os-Francisco-Hinojosa
Jauss, H. R. (1986). Experiencia estética y hermenéutica literaria. Madrid: Taurus.

Macías, E. (2011). Alicia Molina publica El cristal con que se mira. Fondo de Cultura Económica. Recuperado de: https://www.fondodeculturaeconomica.com/Editorial/Prensa/Detalle. aspx? seccion $=$ Detalle\&id desplegado $=45402$

Molina. A. (2000a). El agujero negro. México: Fondo de Cultura Económica.

Molina. A. (1996). El zurcidor del tiempo. México: Fondo de Cultura Económica.

Pennac. D. (2006). Como una novela. Bogotá: Norma.

Reyes, J. J. (2011). Carballido para niños. Siempre! Presencia de México. Recuperado de: http://www.siempre.mx/2011/05/ carballido-para-ninos/

Sánchez, L. C. (2015). Leer por contagio: Francisco Hinojosa. Excelsior. Recuperado de: http://www.excelsior.com.mx/ expresiones/2015/07/24/1036438

Textos de Colores. (2013). Cuando cualquier cosa, yo cuento. Entrevista con Alicia Molina. Textos de Colores. Blog de literatura infantil y juvenil. Recuperado de: http://www.textosdecolores.com/2013/02/ cuando-cualquier-cosa-yo-cuento.html

Vásquez, M. (2002). Fundamentos teóricos para una interpretación crítica de la Literatura Infantil. Comunicación, 12(2): 121-144.

Zuleta, E. (2000). Elogio de la dificultad y otros ensayos. Medellín: Fundación Estanislao Zuleta. 